\title{
Evolution of Annealing Twins and Recrystallization Texture in Thin-Walled Copper Tube During Heat Treatment
}

\author{
Song-Wei Wang ${ }^{1,2} \cdot$ Hong-Wu Song $^{1} \cdot$ Yan Chen ${ }^{1} \cdot$ Shi-Hong Zhang ${ }^{1,2} \cdot$ Hai-Hong Li $^{3}$
}

Received: 5 January 2020 / Revised: 25 February 2020 / Accepted: 1 April 2020 / Published online: 23 June 2020

(c) The Chinese Society for Metals (CSM) and Springer-Verlag GmbH Germany, part of Springer Nature 2020

\begin{abstract}
Thin-walled copper tubes are usually produced by multi-pass float-plug drawing deformation. In general, the annealing treatment subsequently is necessary to release the stored energy and adjusts the microstructure. In this study, an investigation on the evolution of annealing twins as well as textures in the thin-walled ( $\Phi 6 \mathrm{~mm} \times 0.3 \mathrm{~mm})$ copper tube underwent holding time-free heat treatment was reported. Electron backscattered diffraction analysis reveals that a large number of $\Sigma 3$ boundaries $\left(60^{\circ}\langle 111\rangle\right.$ twin relationship) are produced at the early stage of heat treatment, which is due to the lower boundary energy. With the recrystallization proceeding, the migration rate of grain boundaries decreases on account of the grain growth; meanwhile, the unique $\Sigma 9$ boundaries (38.9 $\langle 110\rangle$ relationship) are formed due to the interaction of the $\Sigma 3$ boundaries. As a result, the number fractions of $\Sigma 3$ boundaries and high-angle grain boundaries decrease rapidly. During the grain growth stage, a strong recrystallization texture was formed due to the fact that the grains of Goss orientation have a growth advantage over the others. As a result, the initial copper texture was transferred into the Goss texture in domination.
\end{abstract}

Keywords Copper tube $\cdot$ Annealing twin $\cdot$ Heat treatment $\cdot$ Electron backscattered diffraction (EBSD) analysis .

Recrystallization texture

\section{Introduction}

Since Carpenter and Tamura [1] firstly observed the formation of annealing twins in 1926, it has been found massively in the deformed and then annealed materials. Especially in the face-center cubic (FCC) metals with low or medium stacking fault energies (SFE) (i.e., $\mathrm{Cu}, \mathrm{Ag}$, and $\mathrm{Ni}$ ), annealing twins are frequently observed [2-4]. According to Brandon's criterion, the twin boundary in FCC crystal structure is characterized by rotating the orientation of the parent grain $60^{\circ}$ about $\langle 111\rangle$ axis [5]. The twin boundaries are also

Available online at http://link.springer.com/journal/40195.

Shi-Hong Zhang

shzhang@imr.ac.cn

1 Institute of Metal Research, Chinese Academy of Sciences, Shenyang 110016, China

2 School of Materials Science and Engineering, University of Science and Technology of China, Shenyang 100049, China

3 School of Nuclear Equipment and Nuclear Engineering, Yantai University, Yantai 264005, China defined as $\sum 3$ boundaries that lies in the (111) plane of both crystals, which is one of the special boundaries exploited in grain boundary engineering [6-8]. The annealing twins in these metals with a variety of orientations will significantly affect the microstructures and textures, as well as the properties, i.e., strengthening of the nanostructured $\mathrm{Cu}$ [9], the nucleation of fatigue cracks [10], and the stagnation of grain growth [11].

The forming mechanism of annealing twins during recrystallization and the subsequently evolution during grain growth process are still under research. There are three main mechanisms for twin formation proposed by some researchers. The first theory thought that the crystals already have a twin relationship impinge during growth and then formed the twins $[12,13]$. The second one thought that the twin forms when a misplaced layer of atoms on the (111) plane due to the low stacking fault energy [14-17]. The last theory assumed that the grain boundaries with higher energy transform into a twin boundary and lower energy grain boundaries [18-21]. Therefore, the evolution of annealing twin continuously takes place during recrystallization, and the available evidence cannot discriminate these theories. The availability of recent techniques such as 
electron backscattered diffraction (EBSD) makes it possible to investigate and understand the potential sources for the behaviors found in earlier works. Nowadays, the microstructural behavior and annealing twin evolution in nickel [4, 22], nickel-based superalloy [23, 24], and super-austenitic steel [25] were investigated by EBSD method. The former researches also indicated that not only the materials but also the predeformation process and initial deformation texture are essential for the microstructural evolution during annealing process.

With an aim to understand the recrystallization behavior during the heat treatment, the studies have been carried out to figure out the evolution of texture and the microstructure in pure copper. The effect of cold rolling process on texture evolution of pure copper has been well investigated [26-29] that shows the cube orientation as a recrystallization texture and the formation mechanisms have been proposed as the oriented growth theory. Anand et al. [30] characterized the annealed pure copper sheet after cryo-rolling process and found that with the increase of annealing time, the sample shows a weakening of Brass texture, then exhibits almost random texture, and finally forms the strong cube texture, while the cold-rolled Al- $0.3 \% \mathrm{Cu}$ develops a strong Goss texture during annealing treatment which is related to the oriented nucleate mechanism [31]. Choi et al. [32] proposed the strain energy release maximization model to predict the texture changes of copper electrodeposits after recrystallization. Also, the cold-drawn copper wires have been studied by Baudin et al. [33] after recrystallization, and the results showed the $\langle 100\rangle$ fiber increases at the expense of the other texture components. Nowfal et al. [34] used the synchrotron diffraction method to investigate the local texture gradient through the wall thickness of SF-Cu tubes with an average wall thickness of $10 \mathrm{~mm}$. The structure consists of recrystallized equiaxed grains with twins, and the dominant texture component is the $\{001\}\langle 100\rangle$ cube component.

To the knowledge of the authors, little efforts were taken to study the annealing twins and recrystallization textures of the thin-walled copper tubes. The precision copper tube with a diameter of $6 \mathrm{~mm}$ and a wall thickness of $0.3 \mathrm{~mm}$ was manufactured by the float-plug drawing process, which exhibited a unique deformation microstructure and textures $[35,36]$. The copper tube was widely used in refrigeration industries, due to its excellent thermal conductivity and plasticity. Usually, a heat treatment process is necessary after the deformation in order to release the stored energy of cold work. Thus, the microstructural evolution during recrystallization process is crucial for the final properties [37, 38], such as fatigue resistance, corrosion resistance, and mechanical properties. The purpose of this study is to investigate the annealing twin boundaries as well as recrystallization texture of the copper tube during the heat treatment. Firstly, an evolving structure was obtained by taking the samples at different heating stages. Then, the EBSD technology was utilized to analyze the evolution of microstructure and the textures during the recrystallization process.

\section{Experimental}

Highly purified oxygen-free copper tube billet $(99.997 \%$ pure) was deformed by float-plug drawing process to obtain a $\Phi 6 \times 0.3 \mathrm{~mm}$ final tube as an initial material. The initial tube was cut into the segments about $200 \mathrm{~mm}$ long, and the segments were vacuum packaged with quartz tube to prevent oxidation of surface. Then, the heat treatment was carried out on the segments by using the electric resistance furnace, from room temperature to $900{ }^{\circ} \mathrm{C}$ without holding time. To examine the evolution of microstructure, the single segment was taken out at $200{ }^{\circ} \mathrm{C}, 300{ }^{\circ} \mathrm{C}, 400{ }^{\circ} \mathrm{C}, 500{ }^{\circ} \mathrm{C}$, $700{ }^{\circ} \mathrm{C}$, and $900{ }^{\circ} \mathrm{C}$, respectively, and then water-quenched immediately to maintain the microstructure.

The annealing microstructures were analyzed by EBSD. The samples with size of $5 \mathrm{~mm}$ in length (drawing direction, $\mathrm{DD}), 3 \mathrm{~mm}$ in width (circumferential direction, CD), and $0.3 \mathrm{~mm}$ in thickness (radial direction, $\mathrm{RD}$ ) were cut from the wall thickness of annealed tubes, seen as Fig. 1. The local coordinate system used to identify the direction of inverse pole figure (IPF) and pole figure (PF) is also presented in Fig. 1. The $x$-, $y$-, and $z$-axis correspond to $\mathrm{DD}, \mathrm{CD}$, and $\mathrm{RD}$ direction, respectively. The $\mathrm{RD}$ direction is the normal direction of the observation surface (DD-CD). The DD-CD section was ground slightly to obtain a smooth plane and then polished with diamond paste and finished with ion milling to remove the surface deformation layer. EBSD examinations were carried out using a FEI Nova Nano SEM 430 field-emission scanning electron microscope equipped with a fully automatic HKL Technology EBSD attachment operated at $20 \mathrm{kV}$. The HKL Channel 5 software was used for the EBSD information collection and characterization. EBSD maps were acquired using step sizes of $0.12-0.5 \mu \mathrm{m}$ to analyze the twins and substructures in the observation plane

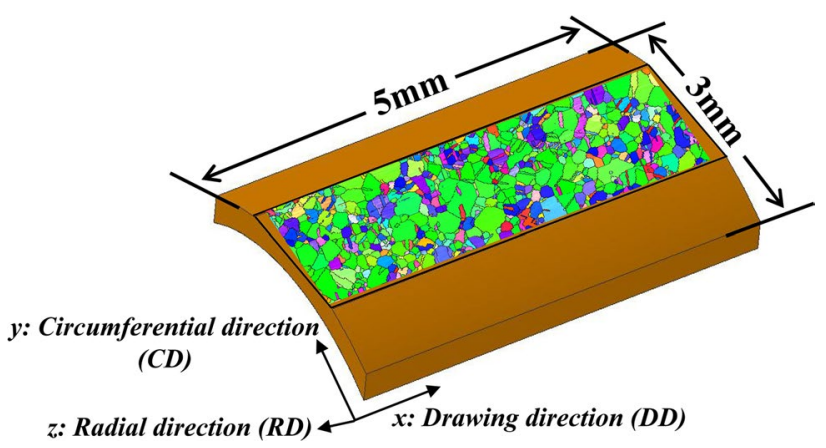

Fig. 1 Observation surface of the samples for EBSD measurement 
containing the drawing direction and circumferential direction (DD-CD). In this study, a critical misorientation angle of $2^{\circ}$ was applied to observe boundaries in the orientation maps, where low-angle grain boundaries (LAGBs) and highangle grain boundaries (HAGBs) were defined as boundaries between grains with misorientation $2-10^{\circ}$ and $>10^{\circ}$, respectively. The average grain size was obtained by using Atex software with twins not included as separate grains. And the Atex software was also used to determine the volume fractions of different texture components, within a spread of $15^{\circ}$ around their respective ideal locations in Euler space.

\section{Results and Analysis}

\subsection{Microstructure Evolution}

Figure 2 reveals the initial microstructure of drawn tube characterized by the orientation map, and it is visible that the grains were elongated and fibered after the drawing deformation. Figure 2a shows the distribution of grain size on the observation surface, with a minimum of $1.28 \mu \mathrm{m}$ and a maximum of $45.05 \mu \mathrm{m}$. Figure $2 \mathrm{~b}$ shows deformation texture in the initial tube, a large proportion of copper $\{112\}\langle 111\rangle$ component, and a weak Goss $\{110\}\langle 001\rangle$ component. Previous studies [36] have reported the texture evolution of copper tube and its relationship with the area reduction during floating plug drawing process.

The EBSD maps character from the copper tube samples after heat treatment at temperatures ranging from 200 ${ }^{\circ} \mathrm{C}$ to $900{ }^{\circ} \mathrm{C}$ (without holding time due to the thin wall thickness) is presented in Fig. 3. Figure $3 a$, b shows that the microstructure remains the drawn fiber at 200 and 300 ${ }^{\circ} \mathrm{C}$, and only a few recrystallization nucleuses are observed in the stretched grains. Figure $3 \mathrm{c}$, d shows a large number of $\sum 3$ boundaries generated at $400-500{ }^{\circ} \mathrm{C}$, and it can be seen that the recrystallization grains grow up significantly. When the temperature reaches to $700{ }^{\circ} \mathrm{C}$, as shown in Fig. 3e, recrystallized grains occupy the initial microstructure. The annealing twins grow with the growth of the recrystallized grains. When the temperature increases to $900{ }^{\circ} \mathrm{C}$, as seen in Fig. 3f, the grains seriously coarsen that leads to the broaden of the annealing twins in it.

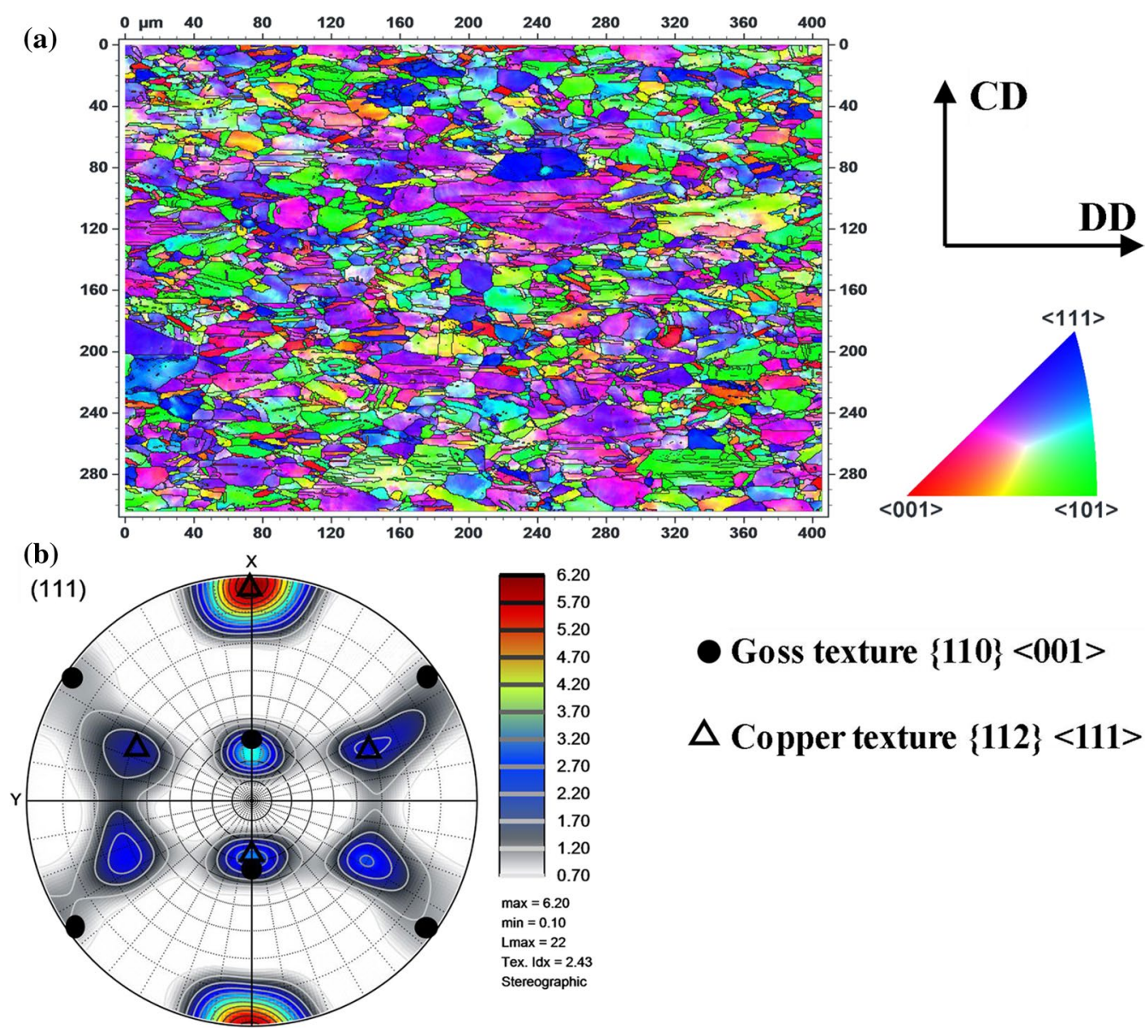

Fig. 2 a EBSD orientation maps of the drawn tube, $\mathbf{b}$ texture components on (111) pole figure 



Fig. 3 EBSD maps from the observation plane (DD-CD) of the tubes annealed at: a $200^{\circ} \mathrm{C}, \mathbf{b ~} 300{ }^{\circ} \mathrm{C}, \mathbf{c} 400^{\circ} \mathrm{C}, \mathbf{d ~} 500{ }^{\circ} \mathrm{C}$, e $700{ }^{\circ} \mathrm{C}, \mathbf{f} 900{ }^{\circ} \mathrm{C}$. Black lines and red lines show HAGBs and $\Sigma 3$ boundaries, respectively

In order to investigate the evolution of recrystallization grains and annealing twins during heat treatment, further analysis was carried on the microstructural parameters, as shown in Fig. 4. According to the shape of curves, the results were divided into three stages using the vertical dashed lines. This can roughly represent the (I) nucleation, (II) normal grain growth, and (III) abnormal grain growth. During stage I, the fraction of high-angle grain boundary and $\sum 3$ boundaries increases sharply, and the average grain size (without twins) increases slightly first and then rises quickly. In stage II, it is seen that the grain size continues to rise at a greater rate, while the HAGBs and $\sum 3$ boundaries decrease slowly. When the temperature comes near 900 ${ }^{\circ} \mathrm{C}$, the grain size increases slowly and the HAGBs and $\sum 3$ boundaries tend to be stable. It is obvious that the evolution of HAGBs content with temperature has the same tendency with $\sum 3$ boundaries.

\subsection{Texture Evolution}

In order to examine the orientation of recrystallization grains during heat treatment, pole figure (PF) was calculated by using Atex software. Figure 5 shows the creation and evolution of different texture components. As shown in Fig. 5a, two texture components can be observed in the initial drawn tube, which are marked as Goss component $\{110\}\langle 001\rangle$ and copper component $\{112\}\langle 111\rangle$. And the intensity of copper component is much higher 


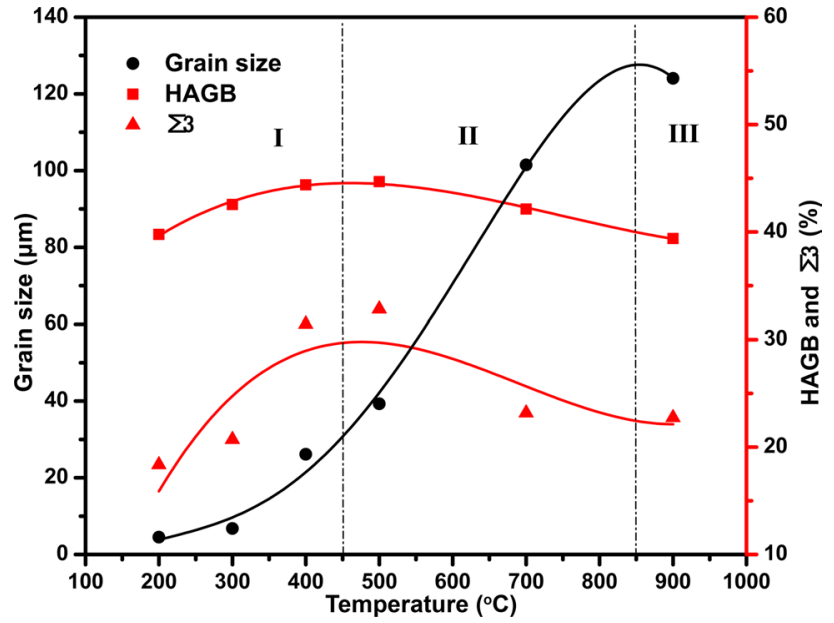

Fig. 4 Evolution of microstructural parameters for the tube samples during heat treatment

than the other one. During the heat treatment process, the maximum intensity of texture decreased first (from 5.9 to 2.9) and then increased again (from 2.9 to 6.9), and the turning point is at $400{ }^{\circ} \mathrm{C}$. Along with this tendency, it is corresponding to the weakening of copper component and enhancing of Goss component. Thus, when the temperature is $900{ }^{\circ} \mathrm{C}$, Goss texture is the main recrystallization texture in the thin-walled copper tube.

\section{Discussion}

\subsection{Formation of the Annealing Twins}

At the first stage of heat treatment, it is clearly observed that a large number of annealing twins are formed. In order to examine the nucleation of annealing twins, high-magnification EBSD was applied on the local position in 300 ${ }^{\circ} \mathrm{C}$ (Fig. 3b, Position 1), as shown in Fig. 6, the black thick line represents the high-angle grain boundaries (HAGBs), while the thin white line represents low-angle grain boundaries (LAGBs). The new grains were largely formed in the stretched grains, and it seems that the nucleation generated at the grain boundaries and grew toward to inner of deformed grains. Figure $6 \mathrm{~b}$ shows the line profile along the black arrow across the new grain in Fig. 6a, and it indicated that the new grain has a twin-orientated relationship $\left(60^{\circ}\right.$ $\langle 111\rangle)$ with deformed matrix. Similar orientation relationship had been reported in some other works [39-41], and it is observed that when a nucleus is formed, it may continue to grow by twinning. It is known that the formation of annealing twins is related to the "growth accident," the coherent twin boundaries generate at migrating grain boundaries due to the stacking errors [42]. Therefore, the annealing twin is likely to form in the FCC metals with low stacking faults energy. Also, the total boundary energy theory (i.e., the energy per unit length of both the grain and twin boundary)

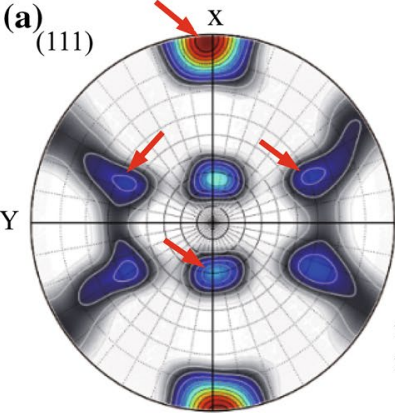

(d)

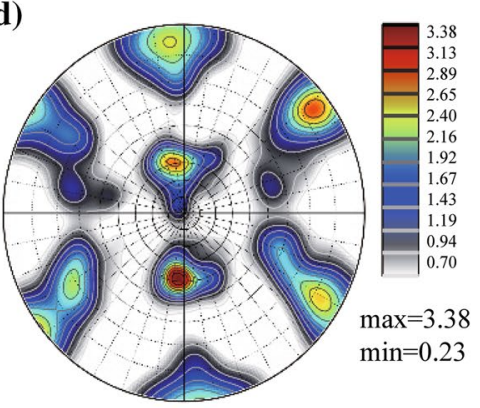

(b)
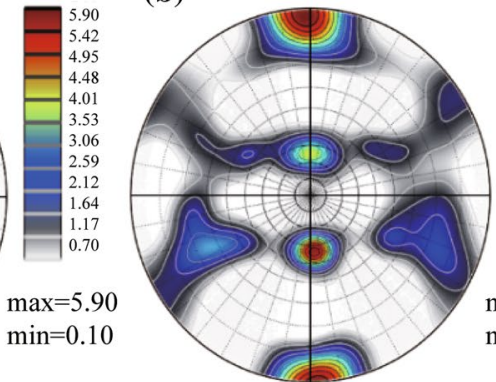

(e)

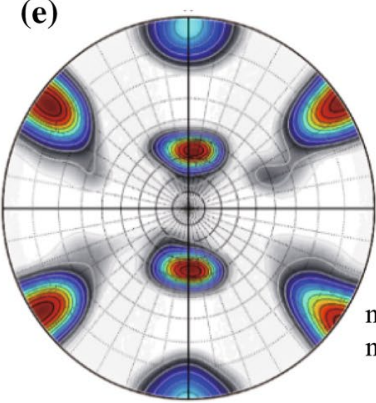

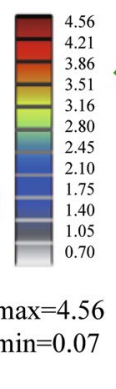

(c)
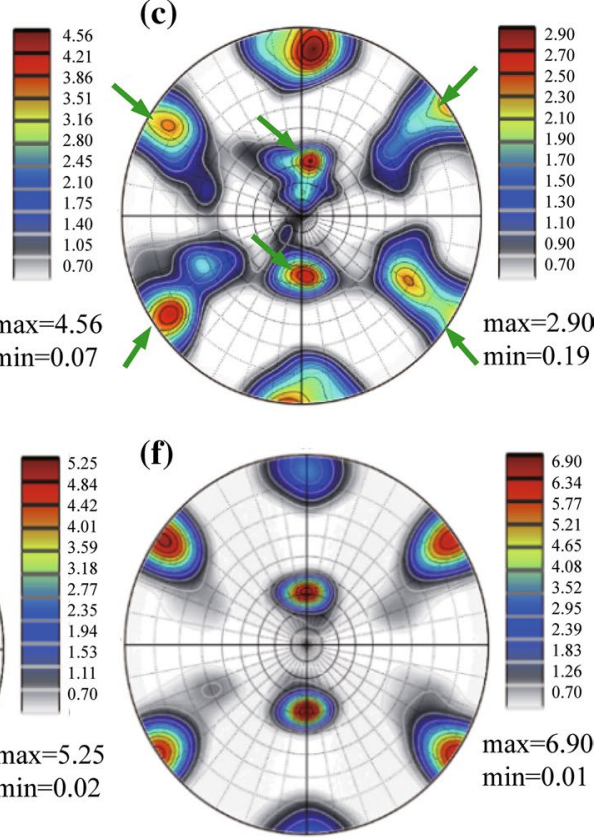

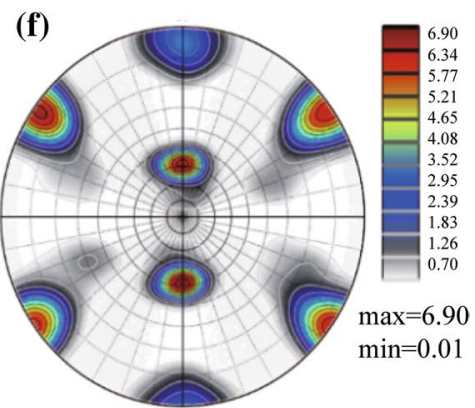

Copper orientation $\{112\}<111>$

Fig. 5 (111) pole figure of samples at various annealing conditions: a $200{ }^{\circ} \mathrm{C}, \mathbf{b} 300{ }^{\circ} \mathrm{C}, \mathbf{c} 400{ }^{\circ} \mathrm{C}, \mathbf{d} 500{ }^{\circ} \mathrm{C}$, e $700{ }^{\circ} \mathrm{C}, \mathbf{f} 900{ }^{\circ} \mathrm{C}$ 

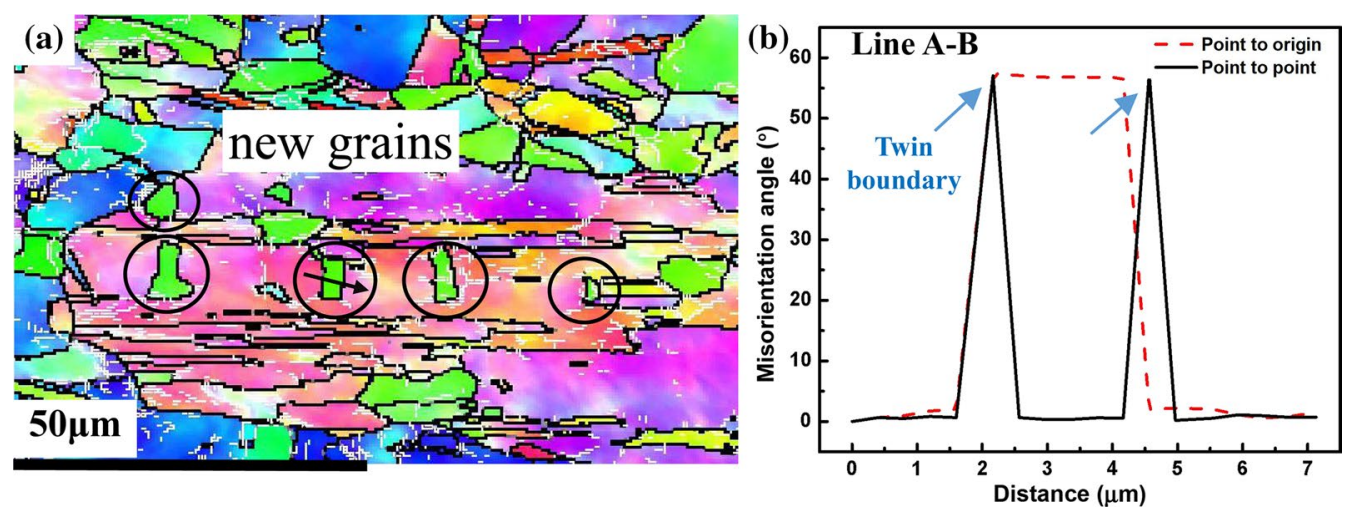

Fig. 6 EBSD map of the local position 1 in Fig. 3b: a the recrystallized grains, b the misorientation angle along the black arrow. The HAGBs and LAGBs are presented by black and gray lines, respectively

can be used to explain why a large number of twins are favorable to exist in the annealing copper. The reduction of energy per unit length, $\Delta E$, can be estimated using following equation [39]:

$\Delta E=\sigma_{\mathrm{GB}} \Delta L_{\mathrm{GB}}+\sigma_{\mathrm{TB}} \Delta L_{\mathrm{TB}}$,

where the $\sigma_{\mathrm{GB}}$ and $\sigma_{\mathrm{TB}}$ are the energy of the grain boundary and the twin boundary, and the $\Delta L_{\mathrm{GB}}$ and $\Delta L_{\mathrm{TB}}$ are the change in lengths of the grain boundary and twin boundary, respectively. During the annealing treatment, there is a reduction in boundary energy [39], and it is reported that in $\mathrm{Cu}$ the twin boundary energy is only $4 \%$ of the normal high-angle grain boundary energy [43]. As a result, the formation of twin grain boundaries will minimize the energy of grain boundaries. This may explain why it is energetically favorable to keep many twins in copper during annealing. However, in the drawn tube, the nucleation is accomplished by the formation of annealing twins alongside the bulged elongated grains, which had highly density of LAGBs, instead of the triple junctions $[4,44]$. Therefore, the fraction of HAGBs and $\sum 3$ boundaries increased sharply at the early stage of the heat treatment.

\subsection{Evolution of Twin Boundaries During Grain Growth Process}

At the stage II of heat treatment, the grain size increased significantly with the increasing of temperature; meanwhile, the fraction of HAGBs and $\sum 3$ boundaries reached the peak value and then decreased slowly. It is easy to understand that the formation of annealing twin requires a moving grain boundary $[15,16,20]$, and it will reflect on the growth of grain size during heat treatment. When the temperature continues to increase, the grown grains begin to encounter with each other, leading to a decrease of grain boundary migration rate [45]. Therefore, it is difficult for the further development of annealing twins. This may be one reason for the drop of density of $\sum 3$ boundaries.

Another reason is the interaction effect of the encountered $\sum 3$ boundaries. It is known that the annealing twins generated randomly alongside the deformed grain boundaries, and as the temperature increased, the twins continue to growth and encounter with the adjacent ones. Then the new $\sum 9$ boundaries $\left(38.9^{\circ}\langle 110\rangle\right.$ relationship) are expected to be produced due to the interaction of two encountered $\sum 3$ twin boundaries as depicted by the following rule [46]:

$\sum 3+\sum 3 \leftrightarrow \sum 9$.

This reaction can also be found in the present heat treatment, and the microstructure at $400{ }^{\circ} \mathrm{C}$ (Position 2 in Fig. 3c) was taken as an example seen in Fig. 7. The HAGBs are illustrated in black lines, the LAGBs in gray lines, the $\sum 3$ boundaries in red lines, and the $\sum 9$ boundaries in pink lines. It is noticed that the boundaries of recrystallized grains are curved and disturbed by the random $\sum 3$ boundaries. The LAGBs were mostly absorbed by the growth of $\sum 3$ boundaries and normal grain boundaries. The ellipse of A, B, C, and D illustrates the transition process. The calculated results by the Channel 5 software showed that $\sum 9$ boundary fraction is only $0.184 \%$ at $300{ }^{\circ} \mathrm{C}$ and then reaches $5.24 \%$ at $400{ }^{\circ} \mathrm{C}$ and $3.76 \%$ at $500{ }^{\circ} \mathrm{C}$, respectively. That is to say, these unique $\sum 9$ misorientation relationships may finally transform into normal HAGBs with the further migration of the twin boundaries [47].

When the grain growth proceeds, the grain boundaries are gradually straightened, and accordingly, the attached annealing twins continuously change with the migration of the grain boundaries. It is obviously that there are three types annealing twins observed at $500{ }^{\circ} \mathrm{C}$, as shown in Fig. 8, the magnification of Position 3 in Fig. 3d. The twin of the type 1 is an island left inner recrystallization grains, the type 2 is the corner twin with a coherent boundary, and the type 3 is 

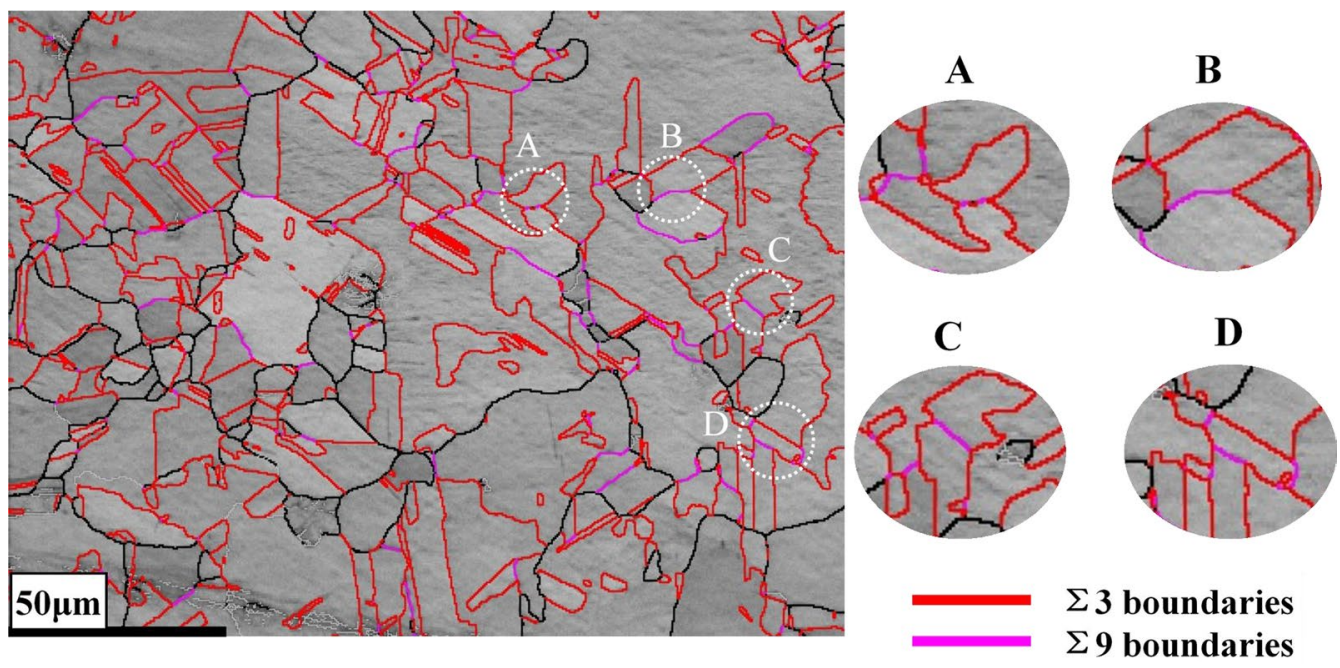

Fig. 7 Grain boundary map of the local position 2 in Fig. 3c. The HAGBs, $\Sigma 3$, and $\Sigma 9$ twin boundaries are represented by black, red, and pink lines, respectively

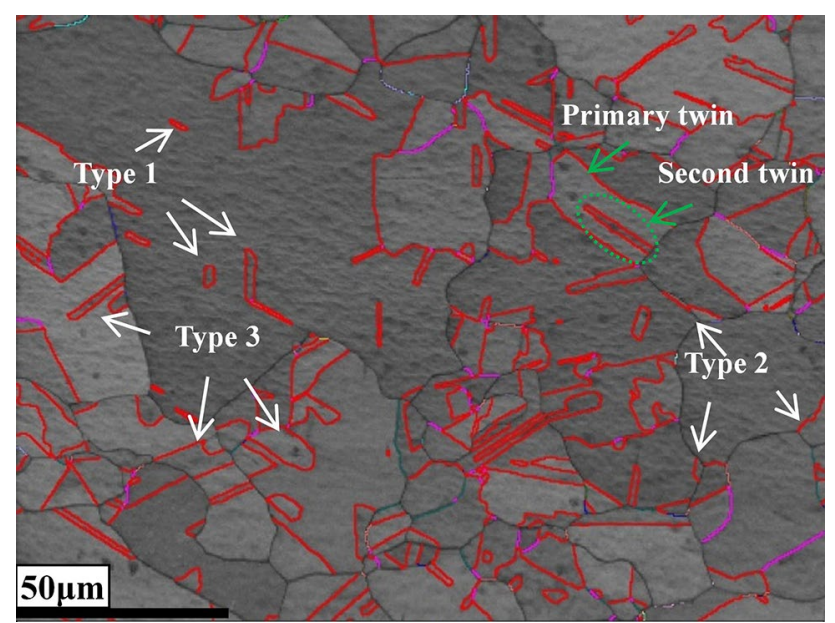

Fig. 8 Grain boundary map of the local position 3 in Fig. 3d. The HAGBs, $\Sigma 3$, and $\Sigma 9$ twin boundaries are represented by black, red, and pink lines, respectively

the band-like twin that spans opposite sides of the grain or terminates within the grain. The type 1 twins almost were nonexistent when the heat-treated temperature reaches to $700{ }^{\circ} \mathrm{C}$ as seen in Fig. 3e. It is assumed that the size of island twins would decrease slowly without energy support and finally have been fully absorbed by the growing grains. But the type 2 twins were produced continuously at the triple junction between grains [43], as seen in Fig. 8, because of the lower grain boundaries energy. The moving direction of the coherent twin boundaries is toward inner grain and lengthens with the grain growth. The primary type 3 twins become thickening and lengthening with the growth of the recrystallization grains and gradually become dominate at the grain growth stage, as shown in Fig. 3e, f. Also, it is noted that new twins of type 3 occurred alongside the recrystallized grain boundaries, and especially, within a primary twin, which are marked in green circle in Fig. 8. These new twins of type 3 generated during the grain growth period may be called second-order annealing twins, but only with a small fraction. This can explain the stabilization of $\sum 3$ boundaries fraction at stage III.

\subsection{Effect of the Interaction of Goss Orientation Grain Growth}

As shown in Fig. 5, the temperature at $400{ }^{\circ} \mathrm{C}$ is a turning point of the transformation from deformation textures to recrystallization textures, which is corresponding to the dominative component from copper $\{112\}\langle 111\rangle$ to Goss $\{110\}\langle 001\rangle$. The Goss component becomes strong as the temperature increases. Previous researches show that during the grain growth after the primary recrystallization, there is an exaggerated growth of some grains with an orientation advantaged at the expense of other newly formed grains [43]. The principal thermodynamic driving force of the grain growth is the tendency to diminish the overall grain boundary 'surface' energy [48]. Thus, as the grains grow in size and decrease in numbers, the grain boundary area diminishes and the total surface energy is lowered accordingly [48]. In addition, the certain oriented grains have a growth advantage to other grains [49], and the strong recrystallization texture develops. As shown in Fig. 9a, the magnification of local Position 4 in Fig. 3f, the growth of Goss grains has an obvious advantage than others in size. In Fig. 9b, the HAGBs were shown in black lines, the LAGBs were shown in white lines, and the twin boundaries were shown 

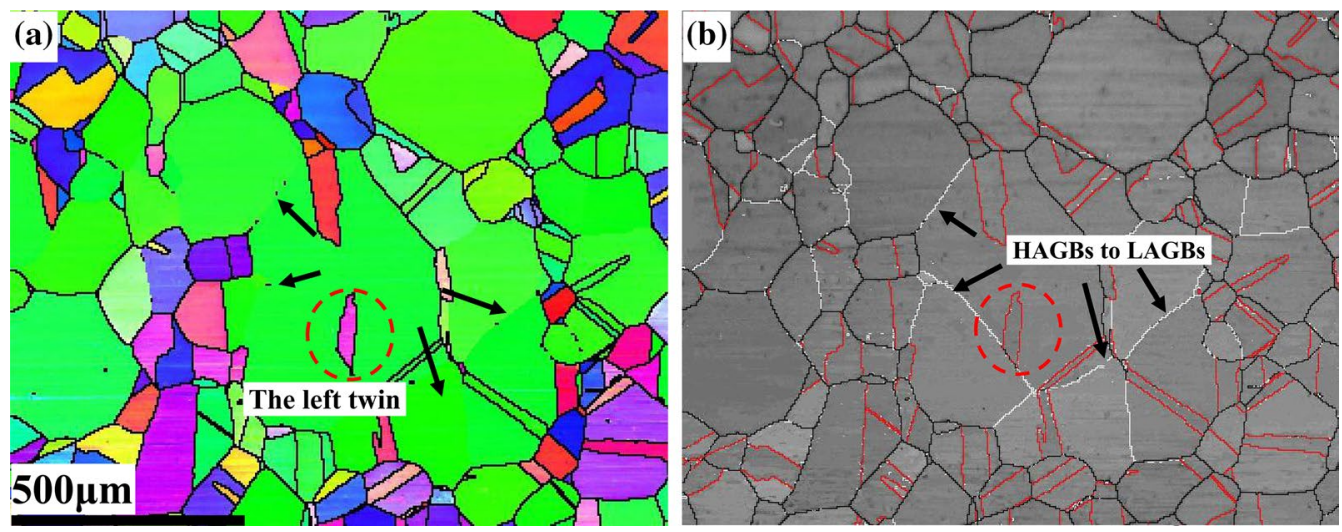

Fig. 9 IPF map and grain boundary map of the local Position 4 in Fig. 4e: a IPF, b grain boundary map. The HAGBs, LAGBs, and $\Sigma 3$ twin boundaries are represented by black, white, and red lines, respectively

in red lines, respectively. The rapid growing of orientatedadvantage Goss grains will encounter each other and form LAGBs (shown as the black arrows) with further increasing annealing temperatures. This will significantly decrease the fraction of HAGBs and the fraction of $\Sigma 3$ concurrently, as shown in Fig. 4. Figure $9 \mathrm{~b}$ illustrates the grains combining process, and similar result was reported in $\mathrm{Cu}-45$ at.\% $\mathrm{Ni}$ alloy [50] that during grain growth the random-orientated grains are consumed by cube-oriented grains, which leads to the obvious decrease of HAGBs. During this combining process, the twin of type 3 marked in red circle was left inner the grown grain and thus transforms to type 1 twin. It is assumed that the left twins will be absorbed by the growth of grain as the temperature continues to rise, or they will be pinned by the impurities and preserved in the matrix.

\section{Conclusions}

(1) The fraction of $\Sigma 3$ boundaries increases sharply at the early stage of heat treatment, which is consistent with the variation trend of HAGBs. The migration of the HAGBs and minimum grain boundary energy theory will contribute to the formation of large number of annealing twins during recrystallization.

(2) At the middle stage of recrystallization process, the migration rate of grain boundaries decreases on account of the grain growth; meanwhile, the unique $\Sigma 9$ boundaries are formed due to the interaction of the $\Sigma 3$ boundaries. As a result, the $\Sigma 3$ boundaries as well as the HAGBs decrease rapidly.

(3) During the grain coarsening stage, a strong recrystallization texture was formed due to the fact that the grains of Goss orientation have a growth advantage over the others. These grains encounter with each other by transforming the common HAGBs into LAGBs as well as consuming the left twins to further growth, which leads to the decrease of the fraction of HAGBs and the fraction of $\Sigma 3$ concurrently.

Acknowledgements This work was financially supported by the Natural Science Foundation of Shandong Province under Grant No. ZR2018MEE005.

\section{References}

[1] H.C.H. Carpenter, S. Tamura, Proc. R. Soc. Lond. A 113, 28 (1926)

[2] D. Field, L. Bradford, M. Nowell, T. Lillo, Acta Mater. 55, 4233 (2007)

[3] T.H. Chuang, H.C. Wang, C.H. Tsai, C.C. Chang, C.H. Chuang, J.D. Lee, H.H. Tsai, Scr. Mater. 67, 605 (2012)

[4] B. Lin, Y. Jin, C.M. Hefferan, S.F. Li, J. Lind, R.M. Suter, M. Bernacki, N. Bozzolo, A.D. Rollett, G.S. Rohrer, Acta Mater. 99, 63 (2015)

[5] D.G. Brandon, Acta Mater. 14, 1479 (1966)

[6] V. Randle, Acta Mater. 52, 4067 (2004)

[7] V. Randle, Mater. Sci. Technol. 26, 774 (2010)

[8] T. Watanabe, J. Mater. Sci. 46, 4095 (2011)

[9] K. Lu, L. Lu, S. Suresh, Science 324, 349 (2009)

[10] C.A. Stein, A. Cerrone, T. Ozturk, S. Lee, P. Kenesei, H. Tucker, R. Pokharel, J. Lind, C. Hefferan, R.M. Suter, A.R. Ingraffea, A.D. Rollett, Curr. Opin. Solid St. M. 18, 244 (2014)

[11] E.A. Holm, S.M. Foiles, Science 328, 1138 (2010)

[12] W.G. Burgers, C.G. Dunn, F. Lionetti, A.J. Shaler, L.D. Jaffe, Trans. AIMME 185, 860 (1949)

[13] W.G. Burgers, J.C. Meijs, T.J. Tiedema, Acta Mater. 1, 75 (1953)

[14] S. Dash, N. Brown, Acta Mater. 11, 1067 (1963)

[15] H. Gleiter, Acta Mater. 17, 1421 (1969)

[16] S. Mahajan, C.S. Pande, M.A. Imam, B.B. Rath, Acta Mater. 45, 2633 (1997)

[17] C.S. Pande, M.A. Imam, B.B. Rath, Met. Trans. A 21, 2891 (1990)

[18] R.L. Fullman, J.C. Fisher, J. Appl. Phys. 22, 1350 (1951)

[19] P.J. Goodhew, Metal Sci. 13, 108 (1979)

[20] M.A. Meyers, L.E. Murr, Acta Mater. 26, 951 (1978)

[21] L.E. Murr, J. Appl. Phys. 39, 5557 (1968) 
[22] X.P. Chen, L.F. Li, H.F. Sun, L.X. Wang, Q. Liu, Mater. Sci. Eng., A 622, 108 (2015)

[23] X.M. Chen, Y.C. Lin, F. Wu, J. Alloys Compd. 724, 198 (2017)

[24] W. Wang, S. Lartigue-Korinek, F. Brisset, A.L. Helbert, J. Bourgon, T. Baudin, J. Mater. Sci. 50, 2167 (2014)

[25] E. Niloofar, Z.H. Abbas, S. Amirali, A.L. Helbert, B. Thierry, Adv. Eng. Mater. 20, 1700928 (2018)

[26] S. Suwas, R.K. Ray, Crystallographic Texture of Materials, 1st edn. (Brian Derby, Manchester, 2014)

[27] C.F. Gu, L.S. Toth, Y.D. Zhang, M. Hoffman, Scr. Mater. 51, 92 (2014)

[28] J.J. Sidor, L.A.I. Kestens, Scr. Mater. 273, 68 (2013)

[29] Z.N. Mao, R.C. Gu, F. Liu, Y. Liu, X.Z. Liao, J.T. Wang, Mater. Sci. Eng., A 186, 674 (2016)

[30] G. Anand, K. Barai, R. Madhavan, P.P. Chattopadhyay, Mater. Sci. Eng., A 114, 638 (2015)

[31] L.F. Shuai, T.L. Huang, G.L. Wu, X. Huang, O.V. Mishin, J. Alloys Compd. 399, 749 (2018)

[32] J.H. Choi, S.Y. Kang, D.N. Lee, J. Mater. Sci. 4055, 35 (2000)

[33] T. Baudin, A.L. Etter, R. Penelle, Mater. Charact. 947, 58 (2007)

[34] N.A. Hamdany, H.G. Brokmeier, M. Salih, Z.Y. Zhong, B. Schwebke, N. Schell, W. Gan, Mater. Charact. 125, 139 (2018)

[35] S.W. Wang, S.H. Zhang, H.W. Song, Y. Chen, Chin. J. Nonferrous Met. 4, 782 (2019)

[36] S.W. Wang, Y. Chen, H.W. Song, A.A. El-Aty, J.S. Liu, S.H. Zhang, Int. J. Mater. Form. (2020). https://doi.org/10.1007/s1228 9-020-01538-Z
[37] K.H. Song, Y.B. Chun, S.K. Hwang, Mater. Sci. Eng., A 454, 629 (2007)

[38] K.K. Alaneme, E.A. Okotete, J. Sci.: Adv. Mater. Devices 4, 19 (2019)

[39] Q.Y. He, T.L. Huang, L.F. Shuai, Y.B. Zhang, G.L. Zhang, X.X. Huang, D.J. Jensen, Scr. Mater. 153, 68 (2018)

[40] G.L. Wu, D.J. Jensen, Acta Mater. 55, 4955 (2007)

[41] T.J. Sabin, G. Winther, D.J. Jensen, Acta Mater. 51, 3999 (2003)

[42] S. Mahajan, Scr. Mater. 68, 95 (2013)

[43] F.J. Humphreys, M. Hatherly, Recrystallization and Related Annealing Phenomena, 2nd edn. (Pergamon, New York, 2004)

[44] W.X. Chen, C. Jia, B.J. Hu, C.W. Zheng, D.Z. Li, Mater. Sci. Eng., A 733, 419 (2018)

[45] W.L. Grube, S.R. Rouze, Can. Metall. Quart. 2, 31 (1963)

[46] L.C. Lim, R. Raj, Acta Mater. 32, 1177 (1984)

[47] H. Beladi, P. Cizek, P.D. Hodgson, Metall. Mater. Trans. A 40, 1175 (2009)

[48] H. Kim, C. Kang, M. Huh, O. Engler, Scr. Mater. 57, 325 (2007)

[49] P.R. Rios, G. Gottstein, L.S. Shvindlerman, Mater. Sci. Eng., A 332, 231 (2002)

[50] H. Tian, H.L. Suo, O.V. Mishin, Y.B. Zhang, D.J. Jensen, J.C. Grivel, J. Mater. Sci. 48, 4183 (2013) 